\title{
Barriers to the implementation of practice guidelines in managing patients with nonvariceal upper gastrointestinal bleeding: A qualitative approach
}

\author{
Sean M Hayes PsyD ${ }^{1}$, Suzanne Murray ${ }^{1}$, Martin Dupuis BA¹, Martin Dawes MD², \\ Ian A Hawes BSP ACPR CCPE ${ }^{3}$, Alan N Barkun MD CM MSc ${ }^{4}$
}

SM Hayes, S Murray, M Dupuis, M Dawes, IA Hawes, AN Barkun. Barriers to the implementation of practice guidelines in managing patients with nonvariceal upper gastrointestinal bleeding: A qualitative approach. Can J Gastroenterol 2010;24(5):289-296.

BACKGROUND/OBJECTIVE: Guidelines for the management of patients with nonvariceal upper gastrointestinal bleeding (NVUGIB) are inconsistently applied by health care providers, potentially resulting in suboptimal care and patient outcomes. A needs assessment was performed to assess health care providers' barriers to the implementation of these guidelines in Canada.

METHODS: Semistructured telephone interviews were conducted by trained research personnel with 22 selectively sampled health care professionals actively treating and managing NVUGIB patients, including emergency room physicians (ER), intensivists (ICU), gastroenterologists (GI), gastroenterology nurses and hospital administrators. Participants were chosen from a representative sample of six Canadian community- and academic-based hospitals that participated in a national Canadian audit on the management of NVUGIB.

RESULTS: Participants reported substantive gaps in the implementation of NVUGIB guidelines that included the following: lack of knowledge of the specifics of the NVUGIB guidelines (ER, ICU, nurses); limited belief in the value of guidelines, especially in areas where evidence is lacking (ER, ICU); limited belief in the value of available tools to support implementation of guidelines (GI); lack of knowledge of the roles and responsibilities of health care professions and disciplines, and lack of effective collaboration skills (ER, ICU and GI); variability of knowledge and skills of health care professionals within professions (eg, variability of nurses' knowledge and skills in endoscopic procedures); and perceived overuse of intravenous proton pump inhibitor treatment, with limited concern regarding cost or side effect implications (all participants).

CONCLUSIONS: In the present study population, ER, ICU and nurses did not adhere to NVUGIB guidelines because they were neither aware of nor familiar with them, whereas the GI lack of adherence to NVUGIB guidelines was influenced more by attitudinal and contextual barriers. These findings can guide the design of multifaceted educational and behavioural interventions when attempting to effectively disseminate existing guidelines, and for guideline implementation into practice.

Key Words: Acid suppressive therapy; Drug therapy; Endoscopy; Gastric; Peptic; Proton pump inhibitors; Stomach
Les obstacles à l'adoption de guides de pratique clinique dans la prise en charge des patients ayant des saignements non variqueux du transit gastroduodénal

HISTORIQUE ET OBJECTIF : Les lignes directrices pour la prise en charge des patients ayant des saignements non variqueux du transit gastroduodénal (SNVTGD) ne sont pas uniformément appliquées par les dispensateurs de soins, ce qui peut entraîner des soins et des issues non optimaux chez les patients. Les chercheurs ont procédé à une évaluation des besoins pour évaluer les obstacles qu'affrontent les dispensateurs de soins pour adopter ces lignes directrices au Canada.

MÉTHODOLOGIE : Un personnel de recherche formé a procédé à des entrevues téléphoniques semi-structurées auprès d'un échantillon sélectionné de 22 professionnels de la santé qui traitaient et prenaient en charge des patients ayant des SNVTGD, y compris les médecins de l'urgence (MU), des intensivistes (USI), des gastroentérologues (GE), des infirmières en gastroentérologie et des administrateurs hospitaliers. Les participants ont été retenus parmi un échantillon représentatif de six hôpitaux généraux et universitaires canadiens qui participaient à une vérification canadienne sur la prise en charge des SNVTGD.

RÉSULTATS : Les participants ont déclaré des lacunes importantes quant à l'adoption des lignes directrices sur les SNVTGD, soit l'absence de connaissances sur les caractéristiques des lignes directrices sur les SNVTGD (MU, USI, infirmières), la croyance limitée à l'égard de la valeur des lignes directrices, notamment dans les secteurs non étayés par des données probantes (MU, USI), la croyance limitée à l'égard de la valeur des outils disponibles pour soutenir l'adoption des lignes directrices (GE), l'absence de connaissances sur les rôles et responsabilités des professions et des disciplines de la santé et l'absence de compétences de collaboration efficaces (MU, USI et GE), la variabilité des connaissances et des compétences des professionnels de la santé au sein de la profession (p. ex., variabilité des connaissances et des compétences des infirmières à l'égard des interventions endoscopiques) et la perception de surutilisation des traitements intraveineux par inhibiteurs de la pompe à protons sans vraiment tenir compte des considérations de coût ou d'effets secondaires (tous les participants).

CONCLUSIONS : Au sein de la population à l'étude, les MU, les USI et les infirmières n'adhéraient pas aux lignes directrices sur les SNVTGD parce qu'ils ne les connaissaient pas ou les connaissaient mal, tandis que les raisons pour lesquelles les GE n'y adhéraient pas étaient davantage influencées par des obstacles attitudinaux et contextuels. Ces observations peuvent orienter la méthodologie des interventions éducationnelles et comportementales multidimensionnelles lorsqu'on tente de diffuser les lignes directrices en place de manière efficace et d'en assurer la mise en pratique.

\footnotetext{
${ }^{1}$ AXDEV Group Inc, Brossard; ${ }^{2}$ Division of Family Medicine, McGill University, Montreal, Quebec; ${ }^{3}$ AstraZeneca Canada Inc, Mississauga, Ontario; ${ }^{4}$ Division of Gastroenterology and Clinical Epidemiology, McGill University Health Centre and McGill University, Montreal, Quebec Correspondence and reprints: Dr Sean M Hayes, AXDEV Group, 8 Place du Commerce, Suite 210, Brossard, Quebec J4W 3H2.

Telephone 450-465-2011, fax 450-465-1155, e-mail hayess@axdevgroup.com

Received for publication September 16, 2009. Accepted October 22, 2009
} 
$\mathrm{T}$ he management of patients with nonvariceal upper gastrointestinal bleeding (NVUGIB) has evolved dramatically over the past 10 years. Examination of physician practices across Canada $(1,2)$ has revealed diverging approaches that would not, in many cases, have been consistent with international guidelines (3). Although these have provided broadly applicable standards for the management of patients with NVUGIB since 2003, recent data suggest shortfalls in their dissemination and implementation across several countries including the United States, Canada, the United Kingdom and elsewhere (4-13). Consequently, predicted improvements in patient outcomes and cost reductions have not reached anticipated levels based on outcomes achieved in randomized clinical trials $(9,14)$. As in other therapeutic areas, it is not surprising to note that the sole release of guidelines is insufficient to effect practice change $(15,16)$.

Furthermore, the optimal approach to realize this aim remains unclear. Traditional didactic educational programs targeting improvement of guideline adherence have not been effective in changing practice $(16,17)$. Interventions involving intensive and multiple interventions have proven more successful (18). Strategies for dissemination and implementation of guidelines are most effective when they are based on target behaviours and carefully tailored to the needs and challenges of behavioural change (19-21).

The multidisciplinary nature of the management of patients with NVUGIB further underscores the need to provide timely knowledge updates, not only for gastroenterologists and general surgeons, but for the entire interdisciplinary team (22) including primary care physicians (such as family physicians and emergency room [ER] physicians), nondigestive disease specialists (such as internists and intensive care unit [ICU] physicians), and nurses and pharmacists. As part of a panCanadian effort studying the implementation and dissemination of NVUGIB guidelines (23), a national qualitative study was undertaken to assess possible needs and barriers to implementation of such consensus recommendations.

\section{METHODS}

\section{Research hypothesis and objectives}

It was hypothesized that specific factors were likely to directly impact the dissemination and uptake of existing guidelines in the management of patients with NVUGIB.

Therefore, a qualitative assessment of barriers to the implementation and application of NVUGIB guidelines in clinical practice across professions was performed. Qualitative research aims to gather an in-depth understanding of human behaviour (24,25). Qualitative research investigates the 'why' and 'how' of behaviours, not just 'what', 'where' and 'when'. Hence, purposive sampling was employed in which smaller, more targeted samples are needed, rather than large random samples (24,25). In particular, the research objective of the present study was to identify and elicit the knowledge, skills, attitudes, behaviours and contextual barriers to the adoption of key NVUGIB guidelines by targeting health care professionals (HCPs) in hospital settings and the issues underlying those barriers.

Key guidelines (listed as numbered in the published consensus document [3]) were identified to be a priority by a group of national experts (1) and included the following: evaluation and resuscitation (guideline 3); risk classification (guidelines 6,
5.1 and 5.2); use of endoscopic therapy (guidelines 7, 10 and 13); use of intravenous proton-pump inhibitor (IV PPI) treatment (guidelines 17 and 18); testing for Helicobacter pylori and eradication therapy (guideline 20) (Table 1).

\section{Data collection}

A qualitative research design was used to facilitate in-depth examination of knowledge and skills, as well as perceived and unperceived attitudes, confidence and contextual issues. In-depth qualitative data collection and analysis enables the elicitation and identification of concepts and variables involved in complex processes such as adherence to clinical guidelines $(24,26)$. In addition, a triangulated research design $(24,27)$ that included a combination of data sources and multiple researcher perspectives in data collection and data analysis was used. The present study included the participation of ER physicians, ICU physicians, gastroenterologists, gastroenterology nurses and hospital directors. Using the framework of Cabana et al (28), offering a rational approach toward improving guideline adherence and a starting point for future research, a semistructured telephone interview was developed to focus on HCPs' challenges and issues underlying adherence to NVUGIB guidelines. This semistructured approach allowed the researchers to suggest a topic of discussion and provided the participants with an opportunity to answer freely with few restrictions (29). Questions were developed around the previously mentioned five management themes that regrouped the prioritized NVUGIB guidelines.

Participants were interviewed by telephone either individually or in homogeneous tandem with another HCP. Each interview lasted between $60 \mathrm{~min}$ and $90 \mathrm{~min}$, and was conducted by experienced interviewers using a semistructured guide that probed for explanatory responses (24,30). Participants were financially compensated for their time. Questions addressing roles and responsibilities, key challenges and barriers (eg, knowledge, attitude, skills, behaviours and context), and applicability of guidelines were asked for each selected guideline described above. The current study followed ethical research processes for the protection of human subjects with respect to their anonymity and confidentiality, and to enhance the integrity of the findings.

\section{Data analysis}

The qualitative data (telephone interviews) were audio taped and independently transcribed. Coding of the qualitative data was based on grounded theory, in which concepts are drawn from the data (26). Initially, open coding was performed with the qualitative data (31), which was reviewed in detail to create an organized system of themes based on the conceptual framework and research questions identified above. Selective coding was subsequently conducted (31) whereby data were systematically coded with respect to core themes identified in the preliminary analysis of the interview data. To establish trustworthiness (32), themes were validated among coders and discrepancies were resolved by discussion until consensus was reached.

\section{Sample}

Participants included a targeted sample of 22 HCPs (Table 2) from six Canadian hospitals (three community based and three academic based) that had participated in the REASON study, 
TABLE 1

Guidelines on which the current needs analysis are based

Evaluation and resuscitation

Immediate evaluation and appropriate resuscitation is critical to proper management

Consider placement of a nasogastric tube in selected patients because the findings may have prognostic value

\section{Risk classification}

Early stratification of patients into low- and high-risk categories for rebleeding and mortality, based on clinical and endoscopic criteria, is important for proper management. Available prognostic scales may be used to assist in decision making

\section{Endoscopic therapy}

Endoscopic hemostatic therapy is not indicated for patients with low-risk stigmata (a clean-based ulcer or a nonprotuberant pigmented dot in an ulcer bed)

Early endoscopy allows for safe and prompt discharge of patients classified as low risk, improves patient outcomes for patients classified as high risk, and reduces resource use for patients classified as either low or high risk

A finding of clot in an ulcer bed warrants targeted irrigation in an attempt at dislodgement. Endoscopic therapy for persistently adherent clots is controversial

Monotherapy, with injection or thermal coagulation, is an effective endoscopic hemostatic technique for high-risk stigmata; however, the combination is superior to either treatment alone

No single method of endoscopic thermal coaptive therapy is superior to another

The placement of clips is a promising endoscopic hemostatic therapy for high-risk stigmata

In cases of rebleeding, a second attempt at endoscopic therapy is generally recommended

Routine second-look endoscopy is not recommended

Intravenous proton pump inhibitors

In patients awaiting endoscopy, empirical therapy with a high-dose proton pump inhibitor should be considered

An intravenous bolus followed by continuous infusion of an intravenous proton pump inhibitor is effective in decreasing rebleeding in patients who have undergone successful endoscopic therapy

Helicobacter pylori testing and treating

Patients with a bleeding peptic ulcer should be tested for $\mathrm{H}$ pylori and receive eradication therapy if present, with confirmation of eradication

Data adapted from reference 3

a national registry that included data from 2020 patients with upper gastrointestinal bleeding collected from 21 institutions in 2005 (1). The hospitals were located in different provinces across Canada - two in Ontario, two in Quebec, one in British Columbia and one in Nova Scotia. Purposive and representative sampling, based on demographic criteria, level of specialization and practice profile were used to select the participants for the present study $(24,25)$ in an effort to assemble a group of institutions with broad generalizability that would be representative of those to be targeted for a subsequent educational and behavioural interventional trial.

\section{RESULTS}

A summary of the different key barriers and issues related to implementation in general, and the five themes of selected guidelines that were investigated is presented in Table 3.

\section{Evaluation and resuscitation}

HCPs' lack of collaboration and teamwork was reported to be a substantive challenge in the appropriate evaluation and resuscitation of patients with NVUGIB, particularly in the ER setting. ER physicians perceived that their primary challenge in collaborative care was the lack of effective communication between themselves and gastroenterologists, and the continuous battle to obtain a gastroenterologist's consultation in the management of acutely ill patients. They reported conflicting and paradoxical requirements by gastroenterologists for an offhour consultation.

They'll (gastroenterologists) say, 'Oh, this guy is too unstable for me to scope. He needs further resuscitation.' Then when you've resuscitated and made them stable they say, 'Well now that he's stable enough, (...) we don't need to come in right now". (...) So, there's sort of a catch 22 situation.
TABLE 2

Sample of health care professionals studied

\begin{tabular}{lcc}
\hline Profession & Participants & Provinces* \\
\hline Emergency room physicians & 5 & 2 \\
Intensive care unit physicians & 4 & 2 \\
Gastroenterologists & 4 & 3 \\
Nurses (eg, endoscopy and gastroenterology & 6 & 3 \\
$\quad$ nurses) & 3 & 3 \\
Directors (eg, Director of Professional Services) & 22 & 4 \\
Total & 22 \\
\hline
\end{tabular}

Data presented as n. *Participating provinces included Ontario, Quebec, British Columbia and Nova Scotia

Similar to ER and ICU physicians, gastroenterologists acknowledged the challenges in the collaboration between the different HCPs involved in the evaluation and resuscitation processes. However, they explained the cause differently. They expressed their concerns about their being called to consult in the evaluation of NVUGIB patients too soon.

One of the frustrations is that they (ER staff) will often call the gastroenterologist right away, without actually resuscitating the patient. And obviously you need to resuscitate the patient before you get the gastroenterologist involved (...) So that's a little bit frustrating. - Gastroenterologist

Another issue faced by ER physicians was the poorly defined roles and responsibilities of each HCP involved in the care of NVUGIB patients at the evaluation stage. Specifically, ER physicians reported a lack of clarity regarding the information needed by gastroenterologists for their consult, such as which questions to ask the patient or what information to seek to support the gastroenterologist's assessment. 
TABLE 3

Five themes of selected guidelines that were investigated, and key barriers and issues related to implementation in general

\begin{tabular}{ll}
\hline Theme & Issues \\
\hline $\begin{array}{l}\text { Guideline implementation } \\
\text { (in general) }\end{array}$ & $\begin{array}{l}\text { General attitude about guidelines: "Guidelines are just guidelines" } \\
\text { The majority of health care professionals perceived that knowledge and application } \\
\text { of guidelines were not optimally monitored in their hospital settings for various } \\
\text { reasons: } \\
\text { Health care professionals' lack of awareness of any monitoring process } \\
\text { Lack of formalized monitoring process } \\
\text { Unwillingness on the part of some pharmacists to challenge physicians' } \\
\text { prescribing behaviours, although they are more informed about the } \\
\text { treatment guidelines than most health care professionals }\end{array} \quad$ Attitude, Context gap \\
\hline
\end{tabular}

1. Initial clinical evaluation and resuscitation
ER and ICU physicians' current practice behaviours are based on "good common

practice", not specific guidelines

The majority of them were not aware of specific guidelines on evaluation and resuscitation for NVUGIB

The majority assume that their practice is already currently aligned with the guidelines

The majority assume guidelines offer no substantive value over and above current practice behaviours

Lack of coordination/collaboration among ER, ICU, and GI

For example, there is a lack of clarity for ER and ICU physicians regarding when $\mathrm{Gl}$ should be involved at the evaluation stage

Lack of agreement between $\mathrm{Gl}$ and ER physicians on the value of the nasogastric aspiration procedure to assess patients with NVUGIB. GI perceived the need to reinforce for ER physicians the necessity of performing this procedure; however, ER physicians are not convinced of this procedure's reliability

ER and ICU physicians acknowledged they do not follow a set protocol with clear criteria to classify patients with NVUGIB

Not aware of specific classification and/or tools available

Not convinced of value to classify patients

Most GI were not convinced of value of Rockall and Blatchford tools

The score will not change the care patients will receive

Experienced/mature physicians believe they do not need the scale

Not convenient to carry around
3. Endoscopy therapy

Lack of agreement among ER, ICU and GI about what "urgent endoscopy" means (ER, ICU)

Lack of information within guidelines to specify timing for intervention on unstable patients $(\mathrm{Gl})$

Variability of nurses' knowledge and skills (GI)

Impact on endoscopy procedure (eg, nurses' knowledge of where the equipment is, and which tools are needed, will facilitate the procedure)

\section{Intravenous proton pump} inhibitors
Most health care professionals acknowledged an overuse of IV PPI

They are not concerned about cost and/or side effects, if any

Lack of knowledge about when to start and stop IV PPI; in particular, before the endoscopy procedure (ER and $\mathrm{GI}$ )

$\mathrm{GI}$ and Directors perceived that everyone is prescribing IV PPI these days (ER, ICU, GI, surgeons), but sometimes incorrectly

In particular, some Directors are concerned that almost every patient is receiving the IV formulation when the oral formulation may be enough
Attitude

Knowledge

Attitude, Knowledge

Attitude

Behaviour, Knowledge

Behaviour, Context gap

Attitude, Knowledge

Attitude

Knowledge, Behaviour

Knowledge

Attitude

Attitude, Behaviour

Attitude

Attitude

Behaviour

Attitude, Knowledge

Knowledge, Context gap

Knowledge, Skills

Behaviour

Attitude, Context gap

Knowledge

Knowledge, Behaviour

Knowledge, Context gap

Knowledge, Attitude

The reliability of the testing for $H$ pylori is questioned (possibility of false negative) (GI) Attitude

Confusion about how to test, and about which test is more accurate (ER, ICU, GI)

Many health care professionals acknowledged their lack of awareness of

Knowledge

Knowledge guidelines on testing for $H$ pylori (ER, GI, nurses)

*Key barriers subdivided into challenges related to knowledge, skills, attitude, behaviour and context gaps. ER Emergency room physicians; GI Gastroenterologists; ICU Intensivists; IV PPI Intravenous proton pump inhibitor therapy; NVUGIB Nonvariceal upper gastrointestinal bleeding

In addition, the majority of physicians were not aware of specific guidelines for evaluation and resuscitation of patients with NVUGIB. They assumed that their current clinical practice behaviours for the evaluation and resuscitation of patients with NVUGIB were aligned with clinical guidelines. They also assumed that specific guidelines for the evaluation and resuscitation of patients with NVUGIB offered no additional value over their current clinical practices. 
Frankly the evaluation, resuscitation is like, baseball and apple pie and these are standard things that we're taught in medical school. The approach to a patient with a bleed is assessing their vitals, etc. So, the guidelines frankly, simply reiterate that we should provide good medical care. I don't think there are any specific guidelines, in my opinion, that are useful.

- Gastroenterologist

\section{Risk classification}

ER physicians recognized their lack of knowledge of the risk classification of patients with NVUGIB. They stressed the importance of their nursing staff in triaging patients. However, it was unclear whether the roles and responsibilities of the specific HCP were in any way explicitly defined. Gastroenterologists did not identify themselves as key players in the risk classification of patients with NVUGIB. According to them, this assessment is the responsibility of ER physicians, in contradiction to what ER physicians indicated.

Recognizing the risk factors for upper GI bleeds would be one challenge, not just as physicians for sure, but also from a nursing perspective. (... ) I would hope that my nursing staff could help me recognize a patient who's at high risk of a serious bleed and we could get them treated more quickly as opposed to someone who's less at risk, let's say a younger person who doesn't have many risk factors.

- ER physician

I went and I tried to talk to the emergency doctors, I took the Blatchford scale and stuck it on the wall but I don't even think it's on the wall anymore. So, the assessment by the emergency physician is strictly clinical, and I don't know what criteria they use really.

- Gastroenterologist

I think the biggest thing is maybe not consistent education, familiarity with bleeds.

- Nurse

Physicians stressed that they did not apply specific guidelines or set protocols in classifying patients with NVUGIB. Some were simply unaware of available tools for risk classification; others stated that those tools were not appropriate in their context. Overall, they were not convinced of the value of adding a tool or a scale to their practice to classify patients with NVUGIB. They reported that the score was useful for documentation purposes only and not for actual patient care.

I'm not really aware of any form of classification system, maybe that's a deficiency in my learning, but we would basically classify them into hemodynamic stability or not and ongoing bleeding or not. (...) So I guess those would be the two criteria that we would use.

- ER physician

The utility of these scoring systems over the top of an experienced physician's general assessment is perhaps marginal in many times.

- Gastroenterologist

\section{Endoscopic therapy}

ER and ICU physicians' main challenge in endoscopic therapy was the availability of resources. Suggesting an endoscopy for a patient with NVUGIB may be optimal, but ensuring that a bed, appropriate nursing staff and a gastroenterologist ready to scope are all available posed a substantive challenge. Despite not being directly involved in the endoscopic procedure, the different contextual issues surrounding this stage were frustrating to ER and ICU physicians.

So our main challenge is getting an endoscopist to see the patient and perform that procedure in a timely fashion and to have the available bed and resources in the hospital to accept that patient and to admit them.

\section{- ICU physician}

Gastroenterologists were clear, "You can't do endoscopic therapy with one person only". However, they acknowledged the substantive challenge in conducting the procedure without adequate support, such as specialized nurses. Furthermore, gastroenterologists and nurses expressed concern over the variability of skills and knowledge among nurses, finding a range of capability. From their perspective, accessing nurses who are knowledgeable and skilled with the equipment, and where to locate it, would greatly facilitate optimal endoscopic therapy.

We are so short-staffed-wise, knowledge-wise, and then there was no follow-up or education post-follow-up as to what could have worked better. There's a learning need here, and it gets very frustrating. - Nurse

Another issue expressed by ER and ICU physicians was the definition of early endoscopy. They described a lack of evidencebased consensus on indications for early endoscopy and a lack of information within the guidelines specifying the timing for intervention of unstable patients. This leads to discord between HCPs involved in the endoscopic therapy stage. In particular, ER physicians and nurses believed that they often have to convince gastroenterologists to perform an endoscopy.

\section{PPI}

Physicians' use of IV PPI treatment varied substantively between hospitals. Some physicians used it indiscriminately for patients with NVUGIB, while other physicians only prescribed it for more serious cases. However, a general consensus that there was a perceived excess of IV PPI prescription for patients with NVUGIB emerged.

We're generous. It's not a written protocol but our unwritten protocol is that anyone coming in with a GI bleed gets the pump inhibitor. $\quad-$ ER physician

The guideline may say, 'Well you don't need to give an IV PPI if there's no high-risk lesions', but there may be some cases where we're not able to scope the patient because the patient is too ill. In those situations we may want to give them an IV PPI drip even though we don't know what the underlying condition is because they're too ill at first to find out. - Gastroenterologist

Physicians' prescription behaviours seemed dependent on their hospital culture. Some hospitals tried to control the use of IV PPI, mainly as a result of cost considerations, while others were less vigilant about their physicians' prescribing behaviours. As a pharmacy director reported:

I'm quite sure that we, as pharmacy, we have dropped off our vigilance as far as trying to make sure that they were using it specifically in that way. (...) I'd say my colleagues have kind of given up.

- Director 
Overall, ER and ICU physicians were not concerned about potential side effects or costs of IV PPI treatment. If physicians had any doubt about NVUGIB, patients received IV PPI treatment by default. The majority acknowledged that this leads to an overuse of IV PPI treatment when the oral treatment might otherwise suffice. However, because the IV PPI treatment was described to be highly effective with no significant negative side effects, and because they were not directly accountable for the costs, the perceived overuse of IV PPI did not constitute sufficient concern for them to change their prescribing behaviours.

Gastroenterologists indicated they were well informed and confident in their knowledge of the specific treatment guidelines for NVUGIB. However, they acknowledged some grey areas, particularly when prescribing IV PPI before performing the endoscopy.

In the patients that come into emergency, I would say that most patients end up getting IV PPI, very few go on oral PPI. (...) And I'd have to argue that it's a grey zone. We don't know exactly what we should do with those patients; we can't really say that they're getting the good or wrong thing.

- Gastroenterologist

\section{Testing for $\mathrm{H}$ pylori and eradication therapy}

ER physicians reported a substantive lack of knowledge about testing when assessing for the presence of $\mathrm{H}$ pylori, especially in the setting of NVUGIB. Nonetheless, each ER physician had a different opinion and preference (eg, endoscopy, biopsy, breath or blood testing). In addition, most of them questioned the reliability of many of the currently available tests.

Any tests that are done, apart from endoscopy, are not that reliable and plus the results are not available to us immediately, so that's one of the reasons why we don't usually test for it in the emergency. Personally I would rarely test for it and those are the reasons why.

- ER physician

In spite of their perceived lack of knowledge, ER physicians were not really concerned or motivated to test for $\mathrm{H}$ pylori and initiate treatment. As one physician stated, "We just don't treat, we don't test for it whatsoever" in the ER. They perceived this issue as the responsibility of the gastroenterologists and/or family physicians. Gastroenterologists acknowledged this perception and were compelled to prescribe $H$ pylori treatment without comprehensive formal testing.

I know the follow-up isn't adequate and these patients are not well assessed for $\mathrm{H}$ pylori afterwards so, I've got one-shot at it. I'll prescribe their $\mathrm{H}$ pylori treatment right then and there.

- Gastroenterologist

\section{DISCUSSION}

There remain substantive knowledge and practice gaps among HCPs, particularly among ER physicians, ICU physicians and nurses. Some of them are aware of the existence of the NVUGIB guidelines but others acknowledge their lack of familiarity and confidence regarding guidelines. Even among gastroenterologists who have good overall knowledge of the treatment guidelines, many are still unclear about specific elements. Beyond the knowledge gaps, HCPs do not fully adhere to guidelines in the care of patients with NVUGIB because of attitudinal barriers. Some do not agree with the concept of adhering to clinical guidelines in general, while others are more concerned about specific issues in relation to NVUGIB clinical practice (eg, question the value of classifying patients using a specific scale). There are also contextual barriers, such as availability of resources (eg, staff and equipment) and lack of communication among the interdisciplinary health care team that are beyond the perceived control of targeted HCPs. The findings indicated that different barriers can be attributed to differential emphases and priorities (15) dependent on the specific health care profession. Specifically, ER physicians, ICU physicians and nurses appear to remain hindered by their lack of awareness and familiarity with the guidelines, whereas gastroenterologists' lack of adherence to NVUGIB guidelines is more influenced by attitudinal and contextual barriers. Residents were not included in the study because the majority of sampled hospitals were not university-based academic institutions. It is important to realize, however, that their involvement in overall management may also drive utilization, such as in the case of PPI prescribing. Their participation was cited as a possible explanation for the observation that time of prescription relates to the appropriateness of PPI prescribing (6).

Previous research has shown that HCPs' adherence to clinical practice guidelines is variable $(15,16)$ and is hindered by a variety of barriers (15). Effective knowledge transfer requires the iterative, timely and effective processes integrating best evidence into the routine practices of patients, practitioners, health care teams and systems (17-21). It may help bridge the consistently demonstrated 'clinical-care gap' between researchbased best clinical practice and the discordant real-world practice of clinicians $(15,22)$, with resulting practice variations that significantly affect health care outcomes and patient quality of life $(33,34)$, and may even decrease morbidity and mortality (34). This gap relates to many factors, including a lack of training in the appraisal of the published literature, information overload, patient expectations, as well as other individual, organizational and peer-group barriers (35-37).

The choice of dissemination and implementation strategy has often been guided by disciplinary background and beliefs of key players rather than consideration of the likely effectiveness of strategies $(37,38)$. Precursors to development of an intervention include defining best evidence, the determination of clinical practice gap and barrier analyses (39), which can stem from many sources (37) including the individual practitioner, policy, other health care practitioners, patients, family members, social contexts and the health care system(s) (37,40-42). Several systematic reviews have stressed the need to understand the forces and variables influencing practice through the use of methods that are practice- or community-based and interactive (41) rather than didactic $(43,44)$, and have concluded that 'magic bullets' to change professional behaviour do not exist, and that the likely best approach is to combine one or more strategies listed above in a manner that is contextsensitive and responsive to feedback and changing needs $(41,45,46)$ while recognizing that the optimal approach may be dependent on the specific topic, patients, professionals or specialty to be addressed (47-49).

There have been few knowledge transfer initiatives related to NVUGIB guidelines despite the marked change in practice and evidence that has occurred over the past 10 years. There 
have, however, been efforts aimed at improving the prevalent inappropriate prescribing of acid suppressants $\left(\mathrm{eg}, \mathrm{H}_{2}\right.$ receptor antagonists or PPIs) in the hospital setting (known to be very high in Canada $[6,8,50]$ and elsewhere $[5,10-13])$ based on available guidelines (51). However, the interventional methodologies have been disparate, with very few baseline assessments of existing barriers. They have included attempts at formulary change, dissemination of pocket cards, seminars and academic detailing, targeted educational programs, the use of a computerized dose template and automatic drug substitution $(14,52-57)$, and have resulted in varying degrees of success in modifying prescribing behaviour or increasing cost savings. One of the most thoroughly documented interventional studies that used a combination of educational and administrative interventions (14) showed a significant absolute reduction in the degree of use for inappropriate indication (ie, an increased proportion of appropriate prescriptions) and a greater improvement in underspending compared with overspending, leading to no significant change in overall costs.

Although the explicit use of validated stratification schemes $(58,59)$ has been widely recommended, it is difficult to measure the impact of their actual use. In the absence of such outcome evidence, professional reticence in using such schemes is difficult to overcome.

The present study was based on self-reports and, accordingly, had the limitations of self-perception and personal insight intrinsic to this form of data collection. However, the multiple researcher perspectives and multiple data sources served to enhance confidence in the findings. Further examination, such as a quantitative approach, would serve to validate and generalize the present study's findings. The objective of the current assessment was to concentrate on challenges and barriers, which may emphasize a negative and pessimistic view of care. The addition of patient representation and others involved in the care of NVUGIB, such as primary care physicians, would provide an additional perspective on perceived professional attitudes, the impact of resource limitations on patient care, and actual patient outcomes beyond the brief hospital stay and interdisciplinary communication.

\section{REFERENCES}

1. Barkun A, Gasco A, Jewell D, Nevin K; the REASON study Investigators. Management of nonvariceal upper GI bleeding (NVUGIB) after guideline publication: The REASON study [Abstract 87]. Can J Gastroenterol 2006;20(Suppl A):80A.

2. Bensoussan K, Fallone CA, Barkun AN, Martel M. A sampling of Canadian practice in managing nonvariceal upper gastrointestinal bleeding before recent guideline publication: Is there room for improvement? Can J Gastroenterol 2005;19:487-95.

3. Barkun A, Bardou M, Marshall JK. Consensus recommendations for managing patients with nonvariceal upper gastrointestinal bleeding. Ann Intern Med 2003;139:843-57.

4. Cooper GS, Kou TD, Wong RC. Use and impact of early endoscopy in elderly patients with peptic ulcer hemorrhage: A populationbased analysis. Gastrointest Endosc 2009;70:229-35.

5. Guda NM, Noonan M, Kreiner MJ, Partington S, Vakil N. Use of intravenous proton pump inhibitors in community practice: An explanation for the shortage? Am J Gastroenterol 2004;99:1233-7.

6. Afif W, Alsulaiman R, Martel M, Barkun AN. Predictors of inappropriate utilization of intravenous proton pump inhibitors. Aliment Pharmacol Ther 2007;25:609-15.

7. Barkun AN, Herba K, Adam V, Kennedy W, Fallone CA, Bardou M. High-dose intravenous proton pump inhibition following endoscopic therapy in the acute management of patients with
The aims of the current study were to identify a number of needs and barriers proposed by professionals in caring for patients with NVUGIB regarded as critical to guideline adherence and patient outcomes. We found that ER physicians, ICU physicians and nurses do not adhere to NVUGIB guidelines because they are neither aware of nor familiar with them, whereas the gastroenterologists' lack of adherence to NVUGIB guidelines is more influenced by attitudinal and contextual barriers. Such knowledge, combined with educational theory identifying effective educational and behaviour change strategies, has guided the creation of a tailored set of educational interventions which, as part of a national initiative in the form of a 44-site cluster randomized clinical trial (ISRCTN85537469), will assist in improving guideline adherence.

DISCLOSURE: Dr Barkun is the recipient of the DG Kinnear Chair in Gastroenterology, McGill University (Montreal, Quebec). Dr Barkun is also a research scholar (Chercheur national) of the Fonds de la Recherche en Santé du Québec.

FUNDING: This study was, in part, supported by an at armslength grant-in-aide provided by AstraZeneca Canada Inc.

ACKNOWLEDEGEMENTS: This needs assessment was conducted by AXDEV Group. Invaluable support was provided by Noémie Chabot, Project Coordinators, Performance Optimization, AXDEV Group. The authors express their appreciation for the contributions of the participants who gave their time and experience to this research. The authors also acknowledge the members of the Steering committee of the REASON-II trial: Dr David Armstrong (McMaster University, Hamilton, Ontario), Dr Martin Dawes (McGill University, Montreal, Quebec), Dr Allan Donner (University of Western Ontario, London, Ontario), Dr Robert Enns (University of British Columbia, Vancouver, British Columbia), Ms Janet Martin (University of Western Ontario), Dr Paul Moayyedi (McMaster University), Dr Joe Romagnuolo (Medical University of South Carolina, South Carolina, USA) and Dr Peter Tugwell (University of Ottawa, Ottawa, Ontario). bleeding peptic ulcers in the USA and Canada: A cost-effectiveness analysis. Aliment Pharmacol Ther 2004;19:591-600.

8. Enns R, Andrews CN, Fishman M, et al. Description of prescribing practices in patients with upper gastrointestinal bleeding receiving intravenous proton pump inhibitors: A multicentre evaluation. Can J Gastroenterol 2004;18:567-71.

9. Hearnshaw S, Logan R, Murphy M, Travis S, Palmer K. Results of the UK audit of 6750 patients with acute upper gastrointestinal haemorrhage. Gut 2009. (In press)

10. Mat Saad AZ, Collins N, Lobo MM, O'Connor HJ. Proton pump inhibitors: A survey of prescribing in an Irish general hospital. Int J Clin Pract 2005;59:31-4.

11. Nardino RJ, Vender RJ, Herbert PN. Overuse of acid-suppressive therapy in hospitalized patients. Am J Gastroenterol 2000;95:3118-22.

12. Parente F, Cucino C, Gallus S, et al. Hospital use of acid-suppressive medications and its fall-out on prescribing in general practice: A 1-month survey. Aliment Pharmacol Ther 2003;17:1503-6.

13. Heidelbaugh JJ, Inadomi JM. Magnitude and economic impact of inappropriate use of stress ulcer prophylaxis in non-ICU hospitalized patients. Am J Gastroenterol 2006;101:2200-5.

14. Kaplan GG, Bates D, McDonald D, Panaccione R, Romagnuolo J. Inappropriate use of intravenous pantoprazole: Extent of the 
problem and successful solutions. Clin Gastroenterol Hepatol 2005;3:1207-14.

15. Cochrane L, Olson C, Murray S, Dupuis M, Tooman T, Hayes S. Gaps between knowing and doing: Understanding and assessing the barriers to optimal health care. J Contin Educ Health Prof 2007;27:94-102.

16. Davis D, Thomson M, Oxman A, Haynes R. Changing physician performance. A systematic review of the effect of continuing medical education strategies. JAMA 1995;274:700-5.

17. Bloom B. Effects of continuing medical education on improving physician clinical care and patient health: A review of systematic reviews. Int J Technol Assess Health Care 2005;21:380-5.

18. Davis D, Taylor-Vaisey A. Translating guidelines into practice: A systematic review of theoretic concepts, practical experience and research evidence in the adoption of clinical practice guidelines. CMAJ 1997;157:408-16.

19. Dobbins M, Robeson P, Ciliska D, et al. A description of a knowledge broker role implemented as part of a randomized controlled trial evaluating three knowledge translation strategies. Implement Sci 2009;4:23.

20. Grimshaw J, Eccles M, Thomas R, et al. Toward evidence-based quality improvement. Evidence (and its limitations) of the effectiveness of guideline dissemination and implementation strategies 1966-1998. J Gen Intern Med 2006;21:14-20.

21. Mazmanian P, Davis D, Galbraith R. American College of Chest Physicians Health and Science Policy Committee. Continuing medical education effect on clinical outcomes: Effectiveness of continuing medical education: American College of Chest Physicians Evidence-Based Educational Guidelines. Chest 2009;135:49S-55S.

22. Davis D. Continuing education, guideline implementation, and the emerging transdisciplinary field of knowledge translation. J Contin Educ Health Prof 2006;26:5-12.

23. Hayes S, Hawes I, Dawes M, Barkun A. Assessment of reasons for non-adherence to nonvariceal upper gastrointestinal bleeding (NVUGIB) guidelines. In: Am Coll Gastroenterol Annual Meeting, Philadelphia, October 12 to 17, 2007.

24. Denzin N, Lincoln Y. Handbook of Qualitative Research. Thousand Oaks: Sage Publications, 2000.

25. Miles M, Huberman A. Qualitative Data Analysis: A Sourcebook of New Methods. Thousand Oaks: Sage Publications, 1984.

26. Strauss A, Corbin J. Basics of Qualitative Research: Grounded Theory Procedures and Techniques. Thousand Oaks: Sage Publications, 1990.

27. Creswell J. Design: Qualitative, Quantitative, and Mixed Approaches. Thousand Oaks: Sage Publications, 2003.

28. Cabana M, Rand C, Powe N, et al. Why don't physicians follow clinical practice guidelines? A Framework for improvement. JAMA 1999;282:1458-65.

29. Rubin H, Rubin I. Qualitative Interviewing: The Art of Hearing Data. Thousand Oaks: Sage Publications, 1995.

30. Patton M. Qualitative Evaluation and Research Methods. Thousand Oaks: Sage Publications, 1990.

31. Neuendorf K. The Content Analysis Guidebook. Thousand Oaks: Sage Publications, 2002.

32. Lincoln Y, Guba E. Naturalistic Inquiry. Thousand Oaks: Sage Publications, 1985.

33. Chassin MR, Galvin RW. The urgent need to improve health care quality. Institute of Medicine National Roundtable on Health Care Quality. JAMA 1998;280:1000-5.

34. Olson KL, Bungard TJ, Tsuyuki RT. Cholesterol risk management: A systematic examination of the gap from evidence to practice. Pharmacotherapy 2001;21:807-17.

35. Maue SK, Segal R, Kimberlin CL, Lipowski EE. Predicting physician guideline compliance: An assessment of motivators and perceived barriers. Am J Manag Care 2004;10:383-91.

36. Grimshaw JM, Eccles MP, Walker AE, Thomas RE. Changing physicians' behavior: What works and thoughts on getting more things to work. J Contin Educ Health Prof 2002;22:237-43.

37. Logan J, Graham I. Toward a comprehensive interdisciplinary model of health care research use. Sci Commun 1998;20:227-46.

38. Grol R. Personal paper. Beliefs and evidence in changing clinical practice. BMJ 1997;315:418-21.
39. Shaw B, Cheater F, Baker R, et al. Tailored interventions to overcome identified barriers to change: Effects on professional practice and health care outcomes. Cochrane Database Syst Rev 2005:CD005470. (Update 2007)

40. Davis D. Continuing education, guideline implementation, and the emerging transdisciplinary field of knowledge translation. J Contin Educ Health Prof 2006;26:5-12.

41. Nutley S, Walter I, Davies H. Improving research use in practice contexts. Using evidence: How research can inform public services. The Policy Press, 2007.

42. Halligan A, Donaldson L. Implementing clinical governance: Turning vision into reality. BMJ 2001;322:1413-7.

43. Davis DA, Taylor-Vaisey A. Translating guidelines into practice. A systematic review of theoretic concepts, practical experience and research evidence in the adoption of clinical practice guidelines. CMAJ 1997;157:408-16.

44. Davis DA, Thomson MA, Oxman AD, Haynes RB. Changing physician performance. A systematic review of the effect of continuing medical education strategies. JAMA 1995;274:700-5.

45. Oxman A, Thomson M, Davis D, Haynes R. No magic bullets: A systematic review of 102 trials of interventions to help health care professionals deliver services more effectively or efficiently. CMAJ 1995;153:1423-31.

46. Bero LA, Grilli R, Grimshaw JM, Harvey E, Oxman AD, Thomson MA. Closing the gap between research and practice: An overview of systematic reviews of interventions to promote the implementation of research findings. The Cochrane Effective Practice and Organization of Care Review Group. BMJ 1998;317:465-8.

47. Chaillet N, Dube E, Dugas M, et al. Evidence-based strategies for implementing guidelines in obstetrics: A systematic review. Obstet Gynecol 2006;108:1234-45.

48. Grupper A, Grupper A, Rudin D, et al. Prevention of perioperative venous thromboembolism and coronary events: Differential responsiveness to an intervention program to improve guidelines adherence. Int J Qual Health Care 2006;18:123-6.

49. Landry MD, Sibbald WJ. Changing physician behavior: A review of patient safety in critical care medicine. J Crit Care 2002;17:138-45.

50. Andrews CN, Levy A, Fishman M, et al. Intravenous proton pump inhibitors before endoscopy in bleeding peptic ulcer with high-risk stigmata: A multicentre comparative study. Can J Gastroenterol 2005;19:667-71.

51. Barkun A, Enns R, Romagnuolo J, et al. Utilization Review of Acid Suppressants (DURABLE) - an audit to assess the utilization of proton pump inhibitors and histamine $\mathrm{H} 2$-receptor antagonists in Canadian hospitals. Gastroenterology 2008;134:A167. (Abst)

52. Moldenhauer ET. Proton-pump inhibitors in a Navy hospital after a formulary change. Am J Health Syst Pharm 2003;60:2367.

53. Mostafa G, Sing RF, Matthews BD, Pratt BL, Norton HJ, Heniford BT. The economic benefit of practice guidelines for stress ulcer prophylaxis. Am Surg 2002;68:146-50.

54. Pitimana-aree S, Forrest D, Brown G, Anis A, Wang XH, Dodek P. Implementation of a clinical practice guideline for stress ulcer prophylaxis increases appropriateness and decreases cost of care. Intensive Care Med 1998;24:217-23.

55. Erstad BL, Camamo JM, Miller MJ, Webber AM, Fortune J. Impacting cost and appropriateness of stress ulcer prophylaxis at a university medical center. Crit Care Med 1997;25:1678-84.

56. Coursol CJ, Sanzari SE. Impact of stress ulcer prophylaxis algorithm study. Ann Pharmacother 2005;39:810-6.

57. Pfau PR, Cooper GS, Carlson MD, et al. Success and shortcomings of a clinical care pathway in the management of acute nonvariceal upper gastrointestinal bleeding. Am J Gastroenterol 2004;99:425-31.

58. Gralnek IM, Barkun AN, Bardou M. Management of acute bleeding from a peptic ulcer. N Engl J Med 2008;359:928-37.

59. Rockall TA, Logan RF, Devlin HB, Northfield TC. Selection of patients for early discharge or outpatient care after acute upper gastrointestinal haemorrhage. National Audit of Acute Upper Gastrointestinal Haemorrhage. Lancet 1996;347:1138-40. 


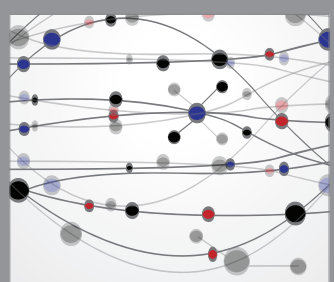

The Scientific World Journal
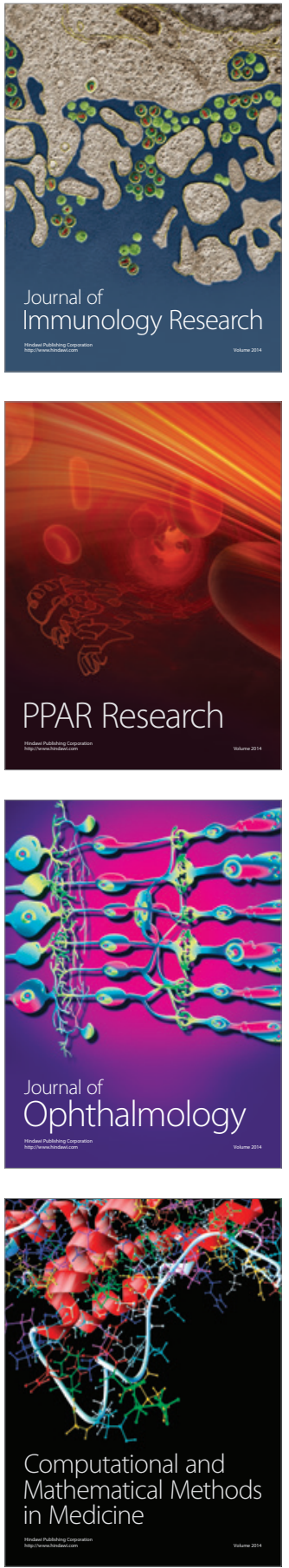

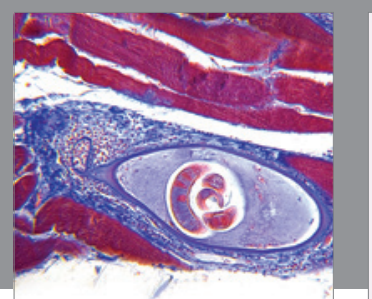

Gastroenterology Research and Practice

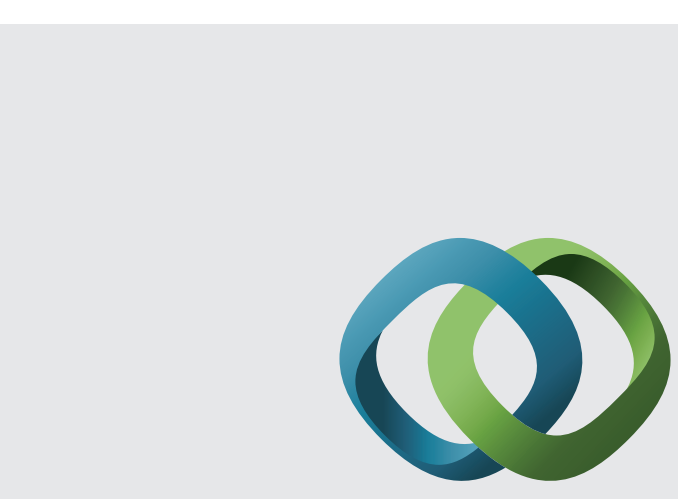

\section{Hindawi}

Submit your manuscripts at

http://www.hindawi.com
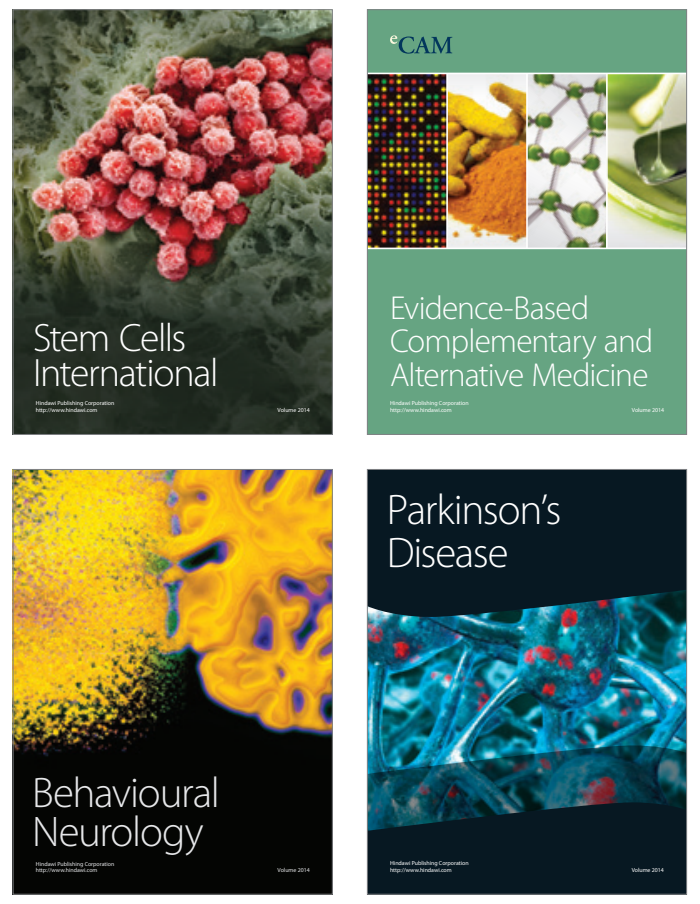
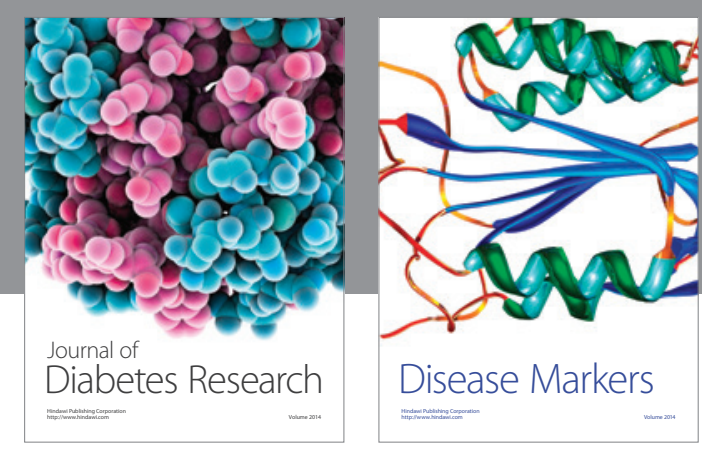

Disease Markers
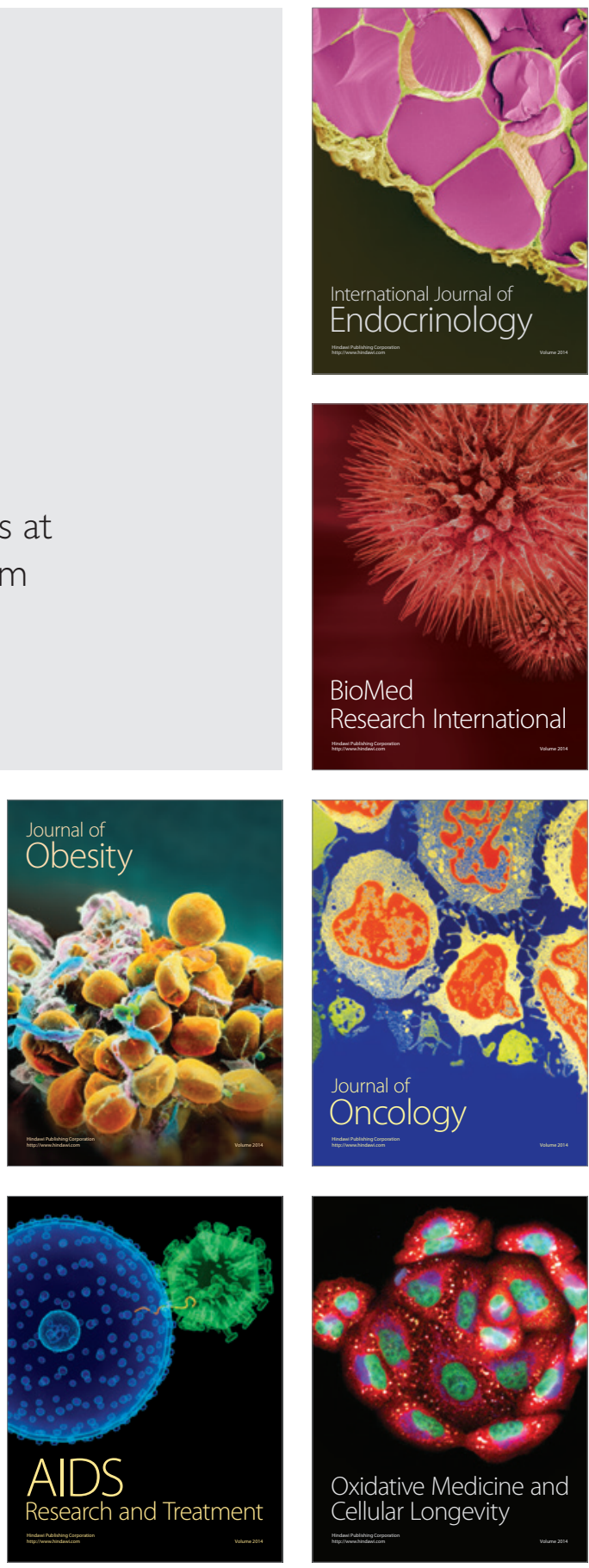